Document downloaded from:

http://hdl.handle.net/10251/122519

This paper must be cited as:

Luján, JM.; Bermúdez, V.; Dolz, V.; Monsalve-Serrano, J. (2018). An assessment of the realworld driving gaseous emissions from a Euro 6 light-duty diesel vehicle using a portable emissions measurement system (PEMS). Atmospheric Environment. 174:112-121. https://doi.org/10.1016/j.atmosenv.2017.11.056

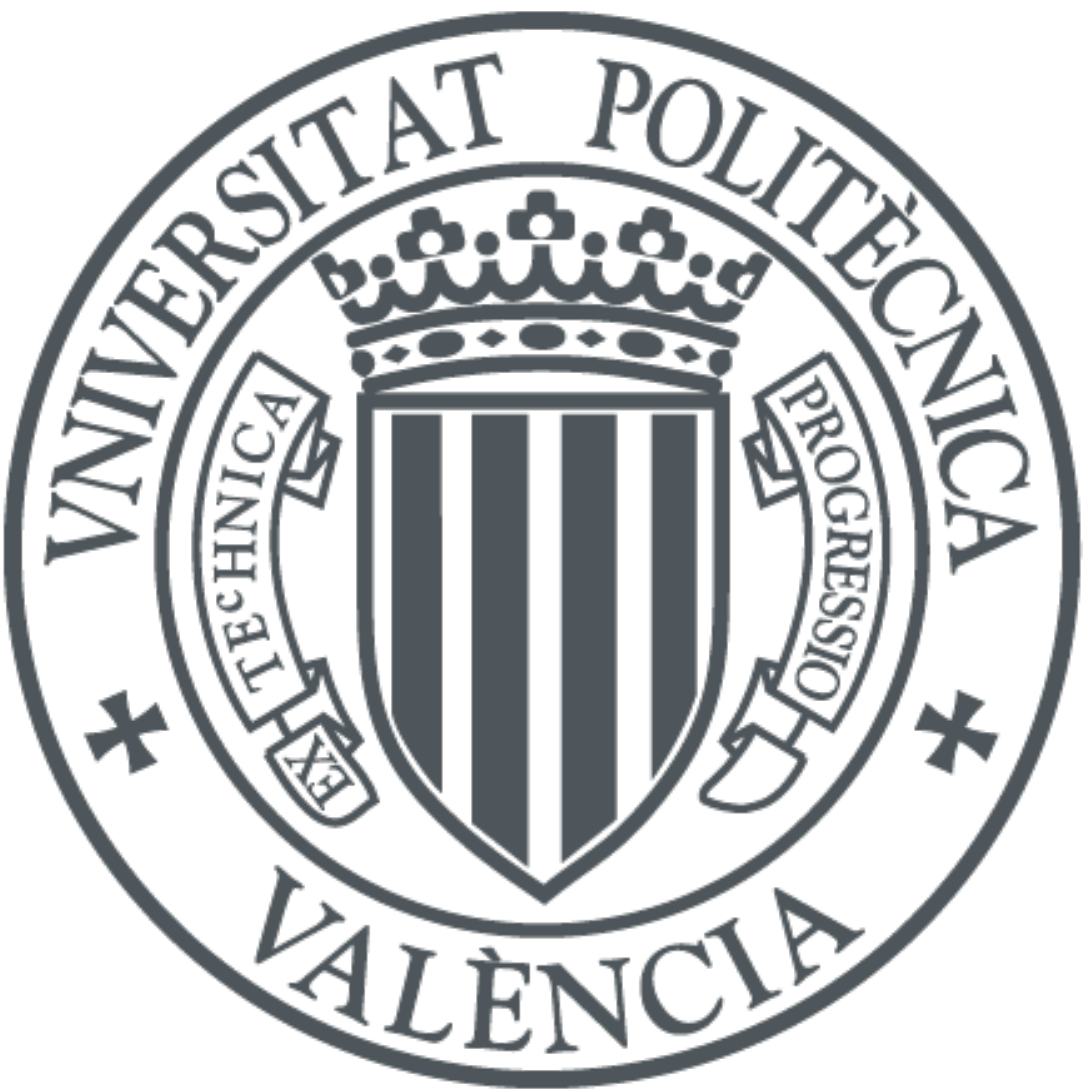

The final publication is available at

https://doi.org/10.1016/j.atmosenv.2017.11.056

Copyright Elsevier

Additional Information 


\title{
An assessment of the real-world driving gaseous emissions from a Euro 6 light-duty diesel vehicle using a portable emissions measurement system (PEMS)
}

Atmospheric Environment, Volume 174, February 2018, Pages 112-121

\section{https://doi.org/10.1016/j.atmosenv.2017.11.056}

\section{José M. Luján, Vicente Bermúdez, Vicente Dolz and Javier Monsalve-Serrano*}

CMT - Motores Térmicos, Universitat Politècnica de València, Camino de Vera s/n, 46022 Valencia, Spain

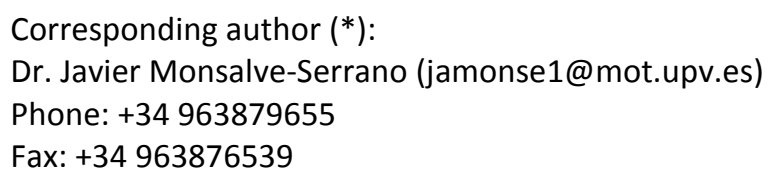

\begin{abstract}
Recent investigations demonstrated that real-world emissions usually exceed the levels achieved in the laboratory based type approval processes. By means of on-board emissions measurements, it has been shown that nitrogen oxides emitted by diesel engines substantially exceed the limit imposed by the Euro 6 regulation. Thus, with the aim of complementing the worldwide harmonized light vehicles test cycle, the real driving emissions cycle will be introduced after 1 September 2017 to regulate the vehicle emissions in real-world driving situations.
\end{abstract}

This paper presents on-board gaseous emissions measurements from a Euro 6 light-duty diesel vehicle in a real-world driving route using a portable emissions measurement system. The test route characteristics follow the requirements imposed by the RDE regulation. The analysis of the raw emissions results suggests that the greatest amount of nitrogen oxides and nitrogen dioxide are emitted during the urban section of the test route, confirming that lower speeds with more accelerations and decelerations lead to higher nitrogen oxides emissions levels than constant high speeds. Moreover, the comparison of the two calculation methods proposed by the real driving emissions regulation has revealed emissions rates differences ranging from $10 \%$ to $45 \%$ depending on the pollutant emission and the trip section considered (urban or total). Thus, the nitrogen oxides emissions conformity factor slightly varies from one method to the other.

\section{Keywords}

Real driving emissions (RDE); Portable emissions measurement system (PEMS); On-road emissions; Emissions conformity factor; Euro 6 emissions standard; Passenger cars

\section{Introduction}

Light-duty vehicles play a major role on the development of modern societies, allowing to cover fundamental requirements such as people and goods transportation [1]. As a result, the vehicle fleet around the world has increased exponentially over the last decades [2]. Among the different powertrain sources, internal combustion engines (ICE) are the most widely used technology, being the source of power for around 90.5 million vehicles produced in 2014 [3]. 
With the aim of reducing the environmental impact of vehicles use [4], stringent regulations are being continuously introduced around the world [5]. The emissions regulations for light-duty vehicles rely on measuring the pollutant emissions emitted by a vehicle over a transient cycle [6][7], which is intended to represent the dynamic conditions experienced during the vehicles use in real life [8]. In 2000 (Euro 3), the socalled New European Driving Cycle (NEDC) was introduced as part of the type approval process for homologating vehicles in Europe [9]. Although this test cycle was developed to reproduce both urban and extra-urban driving conditions, many studies have demonstrated that the driving characteristics proposed by the NEDC are actually far from those experienced during the real-world driving conditions [10]. In particular, the poor range of acceleration-velocity conditions proposed by the NEDC lead to notably lower NOx emissions than those found during on-board measurements in real-world driving routes [11].

Trying to increase the severity of the light-duty vehicles type approval process, the Worldwide harmonized Light duty Test Cycle (WLTC) was developed by the European Commission in 2015 [7]. To develop this new test cycle, around $765.000 \mathrm{~km}$ of real-world driving data from five regions (Europe, India, Japan, Korea and USA) were collected and analyzed [12]. As a result, the WLTC cycle notably widens the driving characteristics in terms of acceleration-velocity conditions and engine map coverage as compared to the NEDC [13]. In spite of that, it has been found that there are some driving characteristics from real-world driving that are missing in the WLTC cycle, as well as different real-world factors such as traffic, ambient conditions, driving behaviors [14] and route severities [15], which results in lower emissions levels than in real-world conditions [16].

To minimize discrepancies between type approval and real-world emissions levels, the Real Driving Emissions (RDE) test procedure will be introduced in September 2017 as a complement of the WLTC cycle [17]. The aim of this new testing method is to control on-road emissions levels from light-duty vehicles by using portable emissions measurement systems (PEMS) [18]. For that purpose, the test routes have to accomplish some characteristics such as ambient conditions, dynamic conditions, driving behavior and equipment precision, among others, described in the RDE regulation [17]. The European Commission already verified this method as a successful application for verifying the in-service conformity and the durability of emission control devices of heavy-duty vehicles through a dedicated research program launched in 2004 [19].

Since the RDE cycle entails more adverse conditions than the type approval WLTC test cycle, the European Parliament has defined the RDE emission limit in form of a not-toexceed (NTE) value dependent on a conformity factor (CF), as shown in equation 1 . To calculate the emissions $\mathrm{CF}$, vehicle manufacturers can choose between two analytical methods proposed by the RDE regulation, the moving averaging window (MAW) method and the standard power frequency (SPF) method, which can result in different CF values.

$$
N T E_{\text {pollutant }}=C F_{\text {pollutant }} \cdot \text { Euro6 }_{\text {limit }}
$$

Up to date, the RDE regulation only establishes a CF of 2.1 for NOx emissions. The Euro 6 regulation establishes $80 \mathrm{mg} / \mathrm{km}$ as a limit for this pollutant, which leads to a NTE value of $168 \mathrm{mg} / \mathrm{km}$ in the RDE test. The CF is expected to be reduced to 1.5 in September 2020 [22]. Future changes will also entail the inspection of the vehicles during their in- 
service life, and not only for newly registered vehicles as is stablished in the current regulation.

This paper aims to assess the on-board emissions from a Euro 6 light-duty diesel vehicle representative of the European market using a PEMS over a test route that fulfills the main requirements imposed by the RDE regulation. In particular, the instantaneous and accumulated values for gaseous emissions will be analyzed, discussing the effect of some conditions that are not taken into account in the RDE procedure for calculating the emissions CF, such as the cold start period. Moreover, the influence of the calculation methods proposed by the RDE regulation on the gaseous emissions rates and on the NOx emissions CF is studied.

\section{Materials and methods}

\subsection{Test vehicle}

A light-duty vehicle representative of the European market was used to perform the onroad emissions measurements. The vehicle equips an in-line four cylinder, 1.5 liter displacement, turbocharged diesel engine with lean NOx trap (LNT) and diesel particulate filter (DPF) aftertreatment systems. The vehicle was type approved to the Euro 6 standard and was registered in January 2016. It has a manual 6-speed transmission, start-stop system and at the beginning of the test had covered $9.800 \mathrm{~km}$. The main characteristics of the vehicle are summarized in table 1 . The test vehicle with the Horiba OBS-ONE-GS12 portable emissions measurement system installed and the calibration equipment are shown in Figure 1.

Table 1. Test vehicle characteristics.

\begin{tabular}{|l|l|}
\hline Manufacturer / model & Nissan / Pulsar \\
\hline Engine & K9K 1.5 dCi \\
\hline Emissions type approval & Euro 6 \\
\hline Maximum power & $82 \mathrm{~kW}$ \\
\hline Maximum torque & $260 \mathrm{Nm}$ \\
\hline Aftertreatment systems & LNT+DPF \\
\hline
\end{tabular}
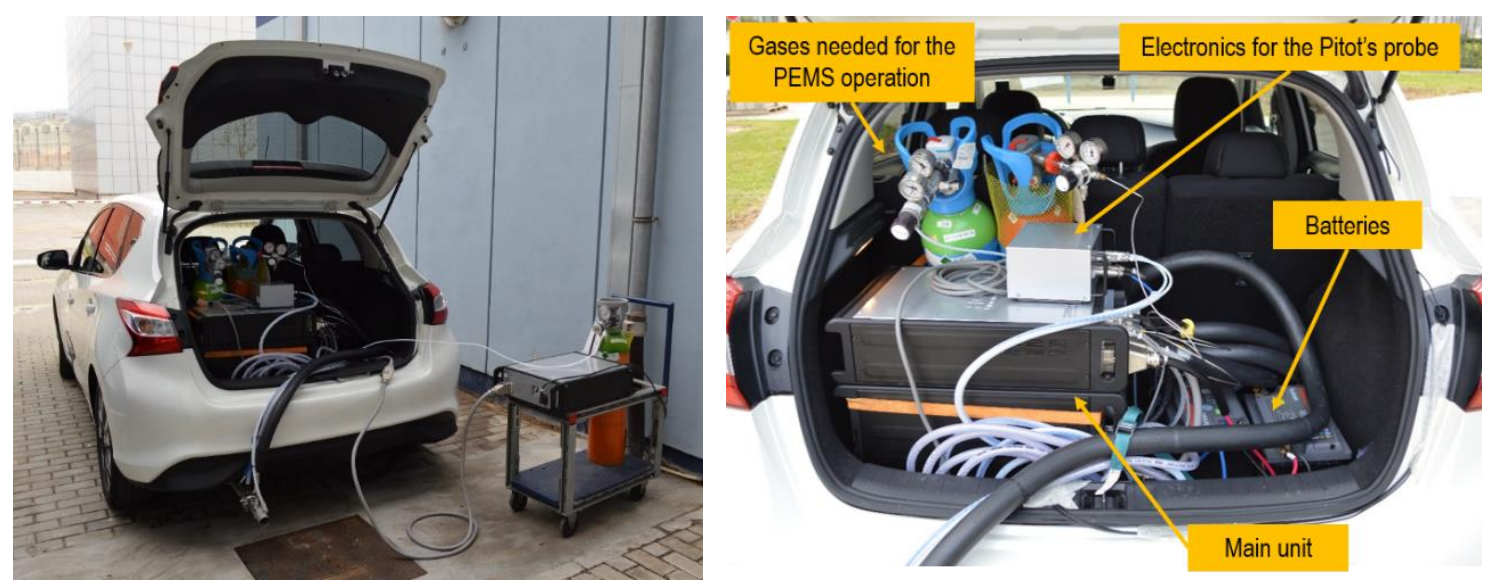

Figure 1. Test vehicle with the portable emissions measurement system installed. The calibration equipment is shown in the left-hand side picture. 


\subsection{Driving route}

The on-road emissions test was carried-out in Valencia (Spain), along the route shown in Figure 2. The test route was designed to fulfill the constraints imposed by the RDE type approval regulation, which differentiates urban $(0$ to $\leq 60 \mathrm{~km} / \mathrm{h}$ ), rural (>60 to $\leq 90$ $\mathrm{km} / \mathrm{h}$ ) and motorway (>90 km/h) trip sections using speed bins [17]. Figure 3 shows the vehicle speed profile of the PEMS test route compared to the NEDC and WLTC cycles. As it can be seen, the total time of the PEMS test is 4.5 and 3 times greater than the NEDC and WLTC, respectively. Also, the number of accelerations during the urban phase is substantially higher. Maximum vehicle speeds are very similar to the WLTC cycle. The summary of the driving route characteristics is shown in table 2. A detailed comparison between the trip requirements imposed by the RDE, and the actual values for the driving route performed in the current investigation, is presented in the Appendix 1 . As can be seen from the altitude profile shown in Figure 4 , the test route was performed in a relatively flat area ( $<50 \mathrm{~m}$ elevation gain over $68 \mathrm{~km}$ ), so that the effect of road gradient is negligible in this study. The positive altitude gain, calculated following the RDE procedure is $321 \mathrm{~m} / 100 \mathrm{~km}$, thus fulfilling the regulation requirements $(<1200 \mathrm{~m} / 100$ $\mathrm{km})$. The air ambient temperature varied between $15-20^{\circ} \mathrm{C}$ along the test, as shown in Figure 4.

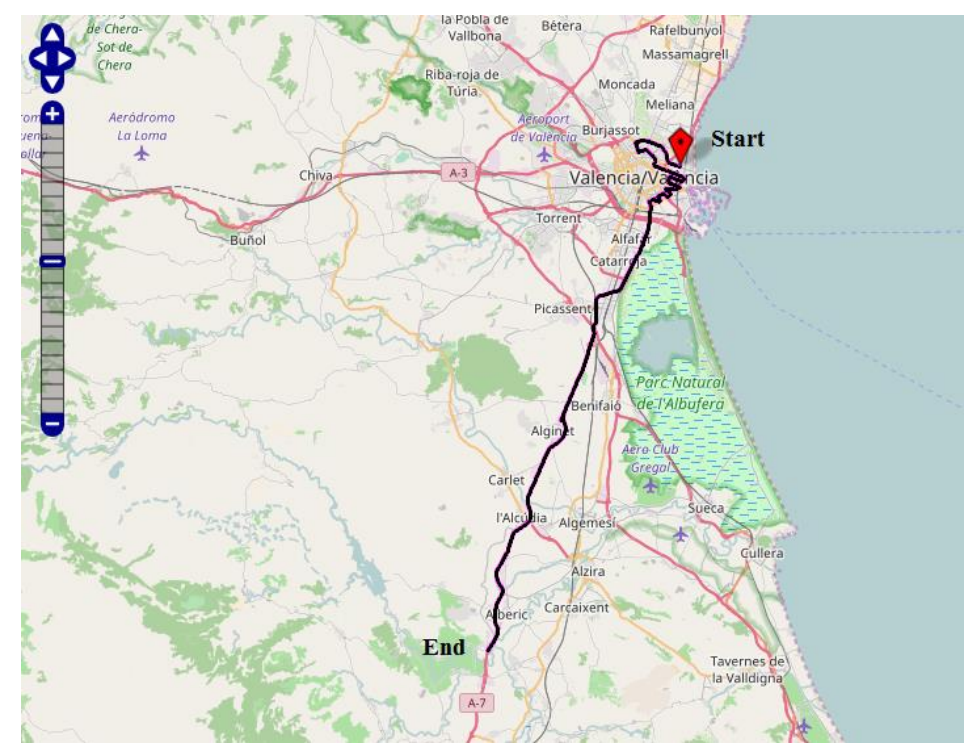

Figure 2. Topographic map of the PEMS test route.
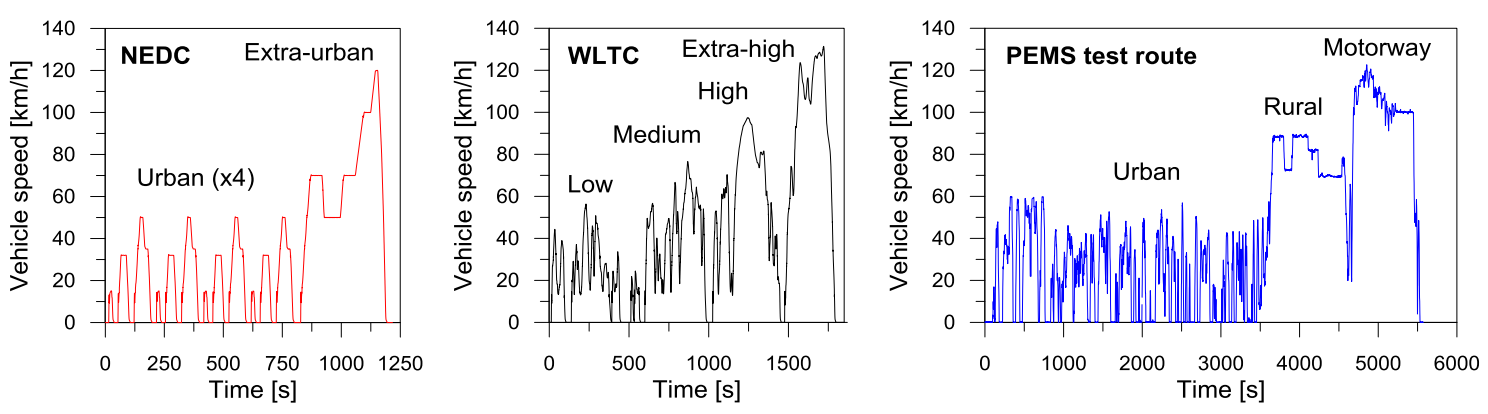

Figure 3. Vehicle speed profile of the NEDC, WLTC and PEMS test route. 
Table 2. Summary of the PEMS test route characteristics.

\begin{tabular}{|l|c|c|c|c|}
\cline { 2 - 5 } \multicolumn{1}{c|}{} & Urban & Rural & Motorway & Total \\
\hline Distance $[\mathrm{km}]$ & $21.7(32.2 \%)$ & $22.05(32.7 \%)$ & $23.61(35 \%)$ & $67.39(100 \%)$ \\
\hline Driving time $[\mathrm{min}]$ & $60.5(65.2 \%)$ & $17.5(18.8 \%)$ & $14.8(16 \%)$ & $92.8(100 \%)$ \\
\hline Average speed $[\mathrm{km} / \mathrm{h}]$ & 21.5 & 76.7 & 95.5 & 43.5 \\
\hline
\end{tabular}

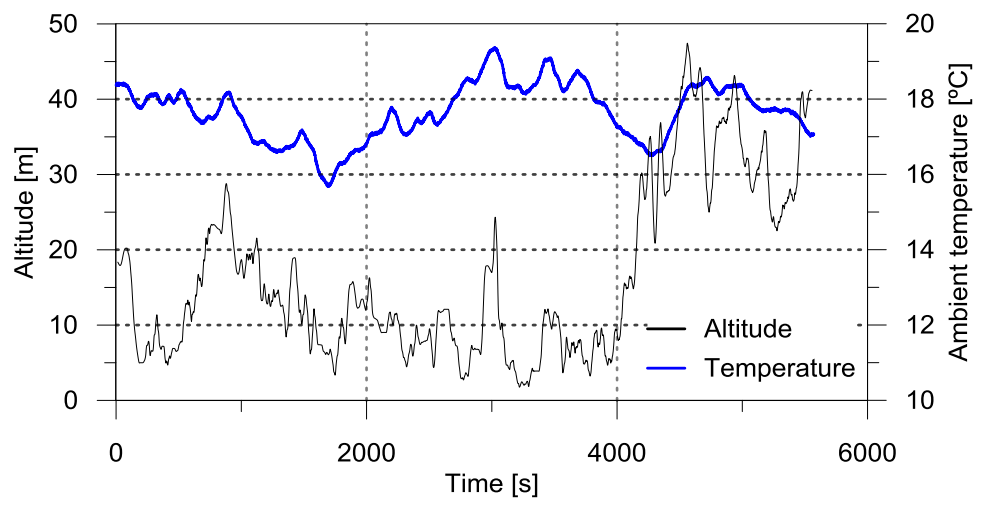

Figure 4. Altitude and ambient temperature profile for the PEMS test route.

Abrupt vehicle accelerations are major cause of $\mathrm{NOx}$ and $\mathrm{NO}_{2}$ emissions in real-world driving conditions [20]. This can be confirmed looking at Figure 5, which shows the NOx and $\mathrm{NO}_{2}$ emissions, and the vehicle acceleration profile during the first 1000 seconds of the PEMS test route. As it can be seen, $\mathrm{NOx}$ and $\mathrm{NO}_{2}$ emissions peaks are clearly linked to the vehicle acceleration peaks.

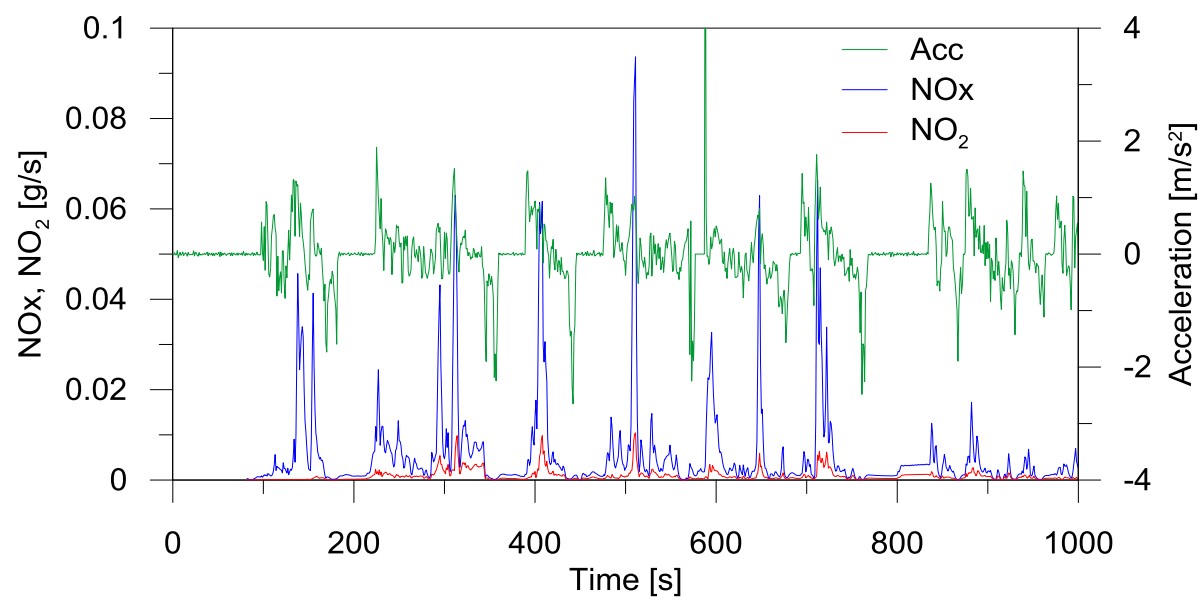

Figure 5. NOx and $\mathrm{NO}_{2}$ emissions and vehicle acceleration during the first 1000 seconds of the PEMS test route.

Figure 6 compares the acceleration-velocity conditions and the engine map coverage of the PEMS test route versus those found in the NEDC and WLTC cycles. As it can be seen, the NEDC cycle proposes very few conditions, being far from those of the PEMS test cycle. By contrast, the acceleration-velocity and engine coverage conditions proposed by the WLTC are more representative of the PEMS test route, but driving characteristics and engine usage for engine speeds below $20 \mathrm{~km} / \mathrm{h}$, those related to city driving, are still missing. 

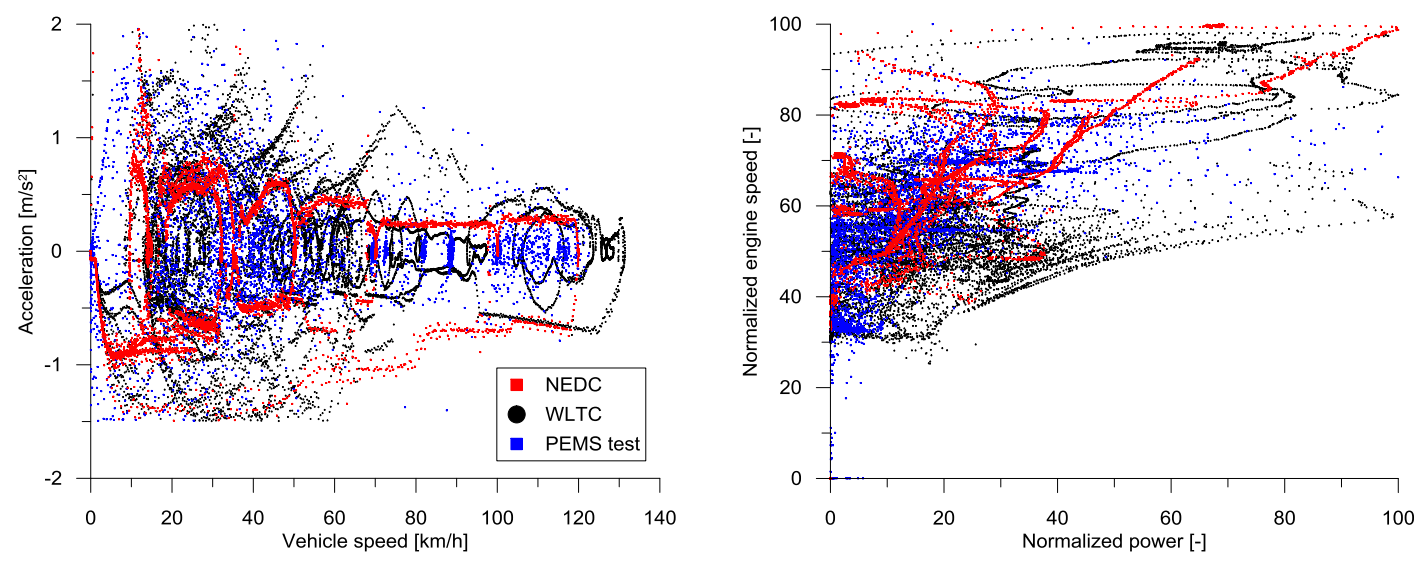

Figure 6. Acceleration as a function of vehicle speed (a) and engine rpm-power map coverage (b) for the NEDC, WLTC and the PEMS test route.

Figure 7 compares the dynamic conditions of the PEMS test route versus the NEDC and WLTC cycles. Figure 7a and 7b show the vehicle speed distributions for the complete cycles and for their different individual phases, respectively. In the case of the PEMS test, 41 different sub-trips have been differentiated. A sub-trip is defined as any part of the test route, in which the vehicle speed is greater than or equal to $2 \mathrm{~km} / \mathrm{h}$ for a period of at least 5 seconds. Individual sup-trips are separated from each other by periods of idling or very slow motion in congested traffic. Thus, the length and number of sub-trips will vary from different PEMS tests because they depend on the route characteristics and the traffic situation. Figure 7c shows the relative positive acceleration (RPA) for the individual phases and complete route of the three cycles. The RPA is a widely used parameter to characterize the dynamic conditions proposed in the engine/vehicle type approval cycles. The RPA accounts the positive vehicle accelerations in the cycle, weighted by the distance driven, driving time and vehicle speed (equation 2). Thus, RPA increases when the driving characteristics proposed in the cycle include a lot of accelerations, which leads to increase both the exhaust emissions and fuel consumption [21]. The calculation of this parameter is also mandatory to check the driving route validity according to the RDE requirements [22].

$$
R P A=\frac{1}{x} \int_{0}^{T} v \cdot a^{+} d t
$$

where $x$ is the total distance, $v$ is the vehicle speed, $a^{+}$is the positive acceleration and $T$ is the total cycle time.

As can be seen in Figure 7a, the WLTC cycle represents better the vehicle speed distributions of the PEMS test route than the NEDC does. However, analyzing the induvial phases of the cycles and PEMS sub-trips (Figure 7b), it is clear that both NEDC and WLTC show a lack of driving phases at low engine speeds as compared to the PEMS test route. 

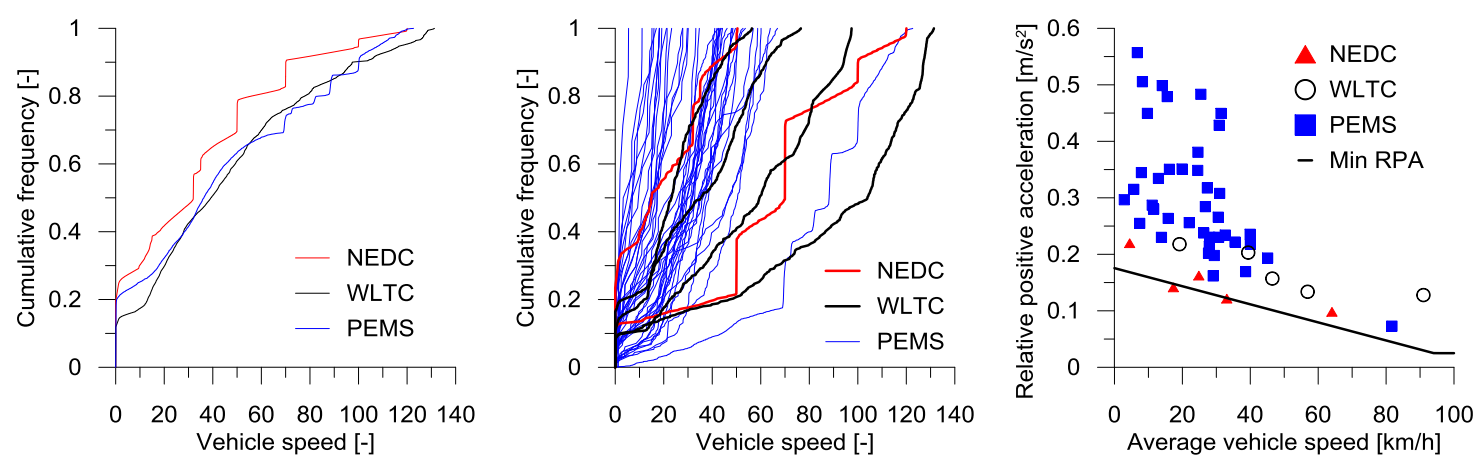

Figure 7. Speed distributions for entire route (a), speed distributions for the different phases and subtrips (b) and relative positive acceleration (c) for the NEDC, WLTC and the test route.

Figure 7c shows that the PEMS test route has a notably wider RPA-speed distribution compared to the NEDC and WLTC cycles. The minimum RPA value imposed by the RDE regulation is depicted in the figure, which varies depending on the mean velocity:

- $\operatorname{RPA}>(-0,0016 \cdot \bar{v}+0,1755)$, for $\bar{v} \leq 94.05 \mathrm{~km} / \mathrm{h}$

- RPA $>0.025$, for $\bar{v}>94.05 \mathrm{~km} / \mathrm{h}$

As it can be seen, all the RPA values for the PEMS test route are above the minimum RPA proposed by the RDE regulation, being the majority of driving conditions found within the range of $0.2-0.4 \mathrm{~m} / \mathrm{s}^{2}$ with mean velocities under $40 \mathrm{~km} / \mathrm{h}$. The NEDC and WLTC cycles are characterized as low RPA, with values between 0.1-0.2 m/s $\mathrm{s}^{2}$ along their phases. Thus, in spite of the driver had a non-aggressive driving behavior during the PEMS test, it is seen that the NEDC and WLTC cycles do not capture the driving characteristics at low vehicle speeds. At these conditions, occurring during city driving, the RPA values for the WLTC and NEDC cycles are up to 3 times lower than those found in the PEMS test. Thus, NOx emissions are expected to be higher in the last case due to higher vehicle acceleration ranges. The change of the driving behavior towards an artificially-relaxed behavior could help to reduce the RPA values near the minimum limit imposed by the RDE regulation, thus contributing to reduce the NOx emissions. However, this task may not be easily achievable considering the traffic conditions from real-world driving.

\subsection{Portable Emissions Measurement System (PEMS)}

A Horiba OBS-ONE-GS12 portable emissions measurement system (PEMS) [23], designed for fulfilling the official requirements imposed by the engine/vehicle certification procedures, has been used to measure concentrations of gaseous emissions ( $\mathrm{CO}, \mathrm{CO}_{2}, \mathrm{THC}, \mathrm{NOx}, \mathrm{NO}_{2}$ ) under real driving conditions. Moreover, several other parameters such as the air-to-fuel ratio, exhaust flow rate, environmental conditions (atmospheric temperature, humidity and pressure) and GPS data (vehicle speed, latitude, longitude and altitude) were monitored to calculate mass emissions. The vehicle speed signal was double-checked using the signal collected through the on board diagnostics (OBD) port. The electrical power needed for the PEMS operation (DC $22 \sim 28$ V) is supplied by two external batteries, so that the engine parameters dependent on the battery voltage are not interfered by the PEMS. The PEMS main unit weight is about $45 \mathrm{~kg}$, plus additional $36 \mathrm{~kg}$ from the batteries. This extra weight is expected to affect 
the emissions and performance values moderately if compared to a case with a single occupant, but it still represents a realistic condition (e.g., driver plus extra occupant). A layout of the different components needed to operate the PEMS is shown in Figure 8.

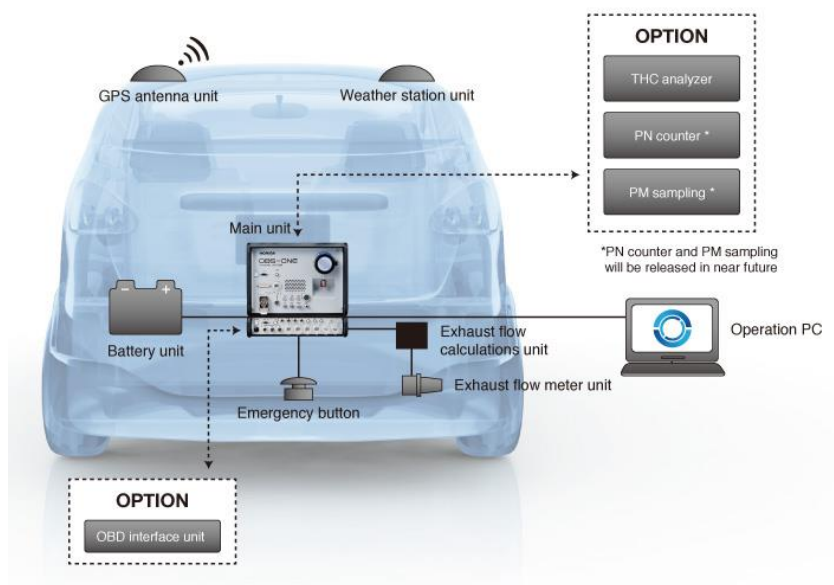

Figure 8. Layout of the different components needed to operate the PEMS [23].

The PEMS uses flame ionization detection (FID) for hydrocarbons (HC) measurements, non-dispersive infrared (NDIR) for $\mathrm{CO}$ and $\mathrm{CO}_{2}$ measurements, and chemiluminescence detection (CLD) for NO, $\mathrm{NO}_{2}$ and NOx measurements. The exhaust flow rate is measured using a Pitot flow meter. The measurement principle and measurement range of each pollutant are shown in table 3 . All emissions were measured on a wet basis, so that no corrections are required for the analysis. The PEMS setup and operation followed the manufacturer recommendations. In this sense, it was warmed up, zeroed and spanned with calibration gas (quad mix) before the test. Measurements were made at a frequency of $10 \mathrm{~Hz}$.

Table 3. Measurement principle and measurement range of each pollutant for the PEMS used.

\begin{tabular}{|l|l|l|}
\hline \multicolumn{1}{|c|}{ Measured variable } & Measurement Principle & \multicolumn{1}{c|}{ Measurement Range } \\
\hline $\mathrm{CO}$ & Heated NDIR & $0-0.5$ to $0-10$ vol\% \\
\hline $\mathrm{CO}_{2}$ & Heated NDIR & $0-5$ to $0-20$ vol\% \\
\hline $\mathrm{NO} / \mathrm{NOx}$ & Heated CLD & $0-100$ to $0-3000 \mathrm{ppm}$ \\
\hline $\mathrm{NO}, \mathrm{NOx}, \mathrm{NO}_{2}$ & Heated-dual CLD & $0-100$ to $0-3000 \mathrm{ppm}$ \\
\hline $\mathrm{THC}$ & Heated FID & $0-100$ to $0-10000 \mathrm{ppmC}$ \\
\hline Exhaust flow rate & Pitot flow meter & $0-2.0$ to $0-65.0 \mathrm{~m}^{3} / \mathrm{min}$ \\
\hline \multirow{2}{*}{ Standard signal measurements } & $\begin{array}{l}\text { Exhaust temperature and pressure, atmospheric } \\
\text { temperature, pressure and humidity, GPS signal, speed }\end{array}$ \\
\hline
\end{tabular}

\section{Results and discussion}

This section analyzes the emissions measurements during the PEMS test route. The first subsection presents the instantaneous and accumulated raw emissions results, which allows to perform a comparison of the real-world driving emissions versus those found in laboratory test cycles. Later, the NOx emissions characteristics and their dependence on the two calculation methods proposed by the RDE regulation are analyzed. Moreover, the impact of the cold start period on the total emissions is discussed there. 


\subsection{Test route emissions}

Figure 9 shows the instantaneous and accumulated emissions of $\mathrm{NOx}, \mathrm{NO}_{2}, \mathrm{HC}, \mathrm{CO}$ and $\mathrm{CO}_{2}$ for the complete route, without removing the cold start period from the raw data. It is worth noting that the start-stop system was disconnected before starting the test and a DPF regeneration occurred at around 5200 seconds after the test start. 

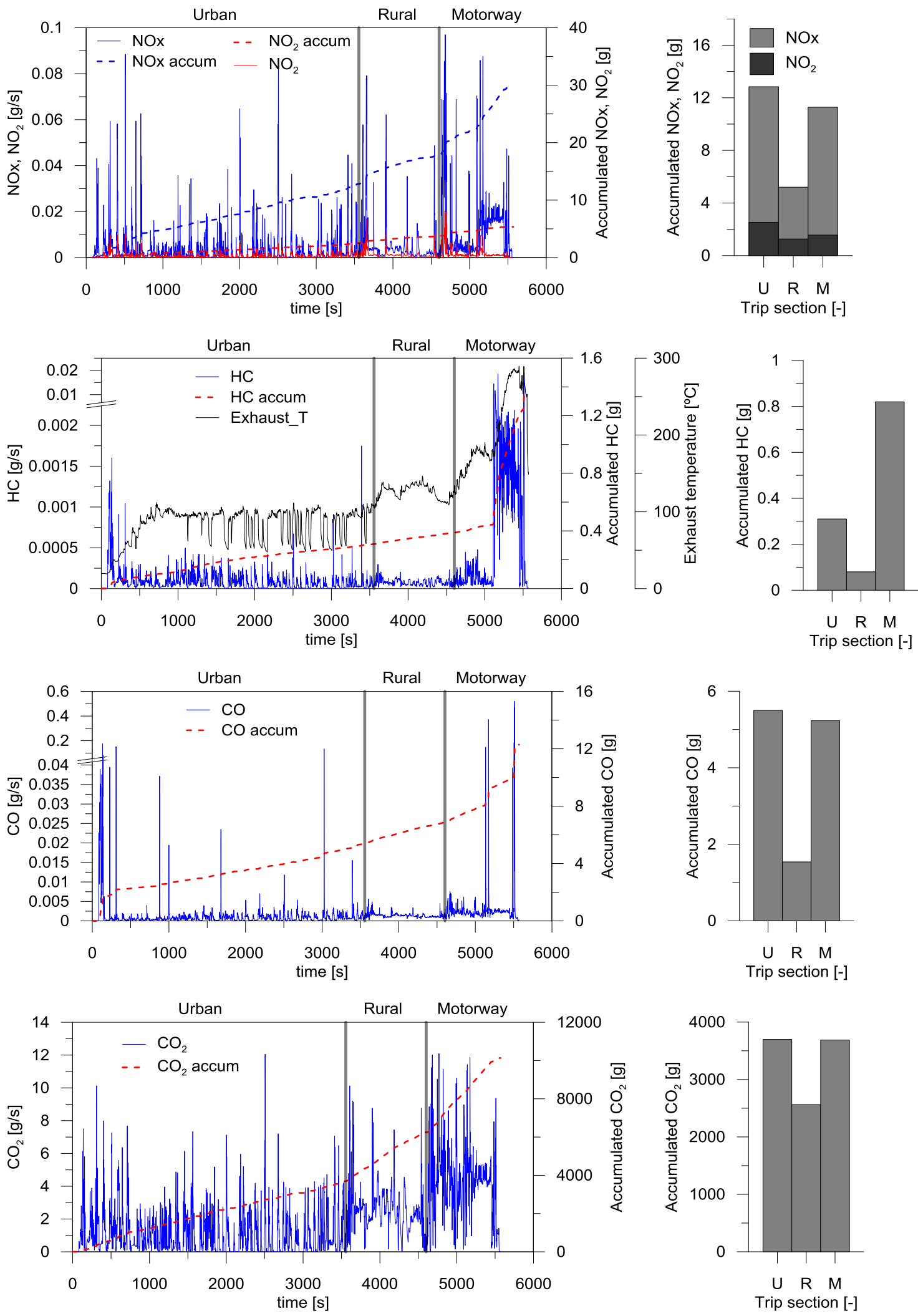

Figure 9. Instantaneous and accumulated emissions of $\mathrm{NOx}, \mathrm{NO}_{2}, \mathrm{HC}, \mathrm{CO}$ and $\mathrm{CO}_{2}$.

From Figure 9a, it is seen that the greatest amount of $\mathrm{NOx}$ and $\mathrm{NO}_{2}$ are emitted during the urban section of the test route. The urban period accounts for the first 3500 seconds of the trip, so that the cold start emissions period (first 300 seconds) is included in this part of the route. Thus, the $\mathrm{NOx}$ and $\mathrm{NO}_{2}$ peaks observed in this phase are expected to 
be consequence of the high RPA occurring in city driving (Figure 7c, low speed region) together with the low LNT efficiency before reaching the light-off temperature. The accumulated NOx emissions in the urban section excluding the cold start period are 11.7 grams, while those accumulated in the motorway section are 11.3 grams. This confirms that lower speeds with more accelerations and decelerations lead to higher NOx emissions levels than constant high speeds. Finally, the figure also shows that the share of $\mathrm{NO}_{2}$ over the total $\mathrm{NOx}$ emissions reaches $17 \%$, with the greatest $\mathrm{NO}_{2}$ share occurring in the rural section (23\%).

Figure $9 \mathrm{~b}$ shows that the total amount of $\mathrm{HC}$ emissions is clearly driven by the $\mathrm{HC}$ emitted in the motorway section, with a $68 \%$ share of the total emissions. The HC emissions increase in this phase is driven by the DPF regeneration occurred around 5200 seconds after the test start, which was detected due to an abrupt rise of the exhaust temperature (Figure 9). On the other hand, it is seen that HC peaks during the first 300 seconds (cold start period) are greater than the rest of the urban phase. Since driving conditions during all this phase are similar, this confirms that these peaks result from the low activity in the diesel oxidation catalyst (DOC). CO emissions behavior (Figure 9c) is homologous to that of $\mathrm{HC}$, with high emission peaks at the beginning of the test due to cold conditions, and with the greatest peaks occurring in the motorway section.

The average grams of carbon dioxide per kilometer $\left(\mathrm{gCO}_{2} / \mathrm{km}\right)$ over the total trip is 151 (Figure 9d), thereby exceeding the $94 \mathrm{gCO}_{2} / \mathrm{km}$ as specified during laboratory NEDC testing for the tested vehicle [24]. The total amount of $\mathrm{CO}_{2}$ in the urban and motorway sections is nearly equal, being the $\mathrm{CO}_{2}$ emissions for the rural section $30 \%$ lower than in the other cases. The high $\mathrm{CO}_{2}$ emitted (high fuel consumption) in the urban section is related to the inefficient operation of the engine with consecutive idling periods. On the other hand, since the dynamic conditions in the rural and motorway section are very similar, the $\mathrm{CO}_{2}$ difference should be mainly related to engine efficiency differences through the operating points demanded during the route.

\subsection{Influence of the calculation method on the NOx conformity factor}

Because of their harmfulness, NOx emissions are the most persecuted emissions from diesel vehicles [25]. As suggested in Figure 5, NOx emissions in real driving conditions are mainly consequence of abrupt vehicle accelerations, even they occur at low average speed conditions. This statement can be confirmed in Figure 10, where the NOx emissions for the 41 sub-trips of the PEMS test route are represented as a function of the RPA and average speed. The bubble sizes increase linearly with the NOx emissions rate, being the maximum and minimum values 2.22 and $0.27 \mathrm{~g} / \mathrm{km}$, respectively.

From Figure 10, it is seen that the greatest NOx emissions rates occur at low average speeds $(<20 \mathrm{~km} / \mathrm{h})$ with high RPA $\left(>0.4 \mathrm{~m} / \mathrm{s}^{2}\right)$. The sub-trips associated to these conditions occurred more than 2000 seconds after the test started, when the LNT aftertreatment system was already operating at its maximum efficiency [26]. The highest NOx emission rate occur in the sub-trip number 37 (3300 seconds after the test started), being consequence of a moderate acceleration at a very low average vehicle speed. By contrast, the sub-trip encompassing the rural and motorway phases shows driving conditions of high average vehicle speed and low RPA, thereby leading to a low NOx emission rate. Looking at the NOx emissions of the sub-trips occurring during the cold start period, it can be seen that the NOx rates (bubble sizes) are higher than their 
surrounding sub-trips, which have similar velocity-RPA conditions. This confirms the effect of the LNT efficiency on the NOx emissions rate and the importance of minimizing the light-off temperature of this system to reduce the total NOx emissions of the cycle.

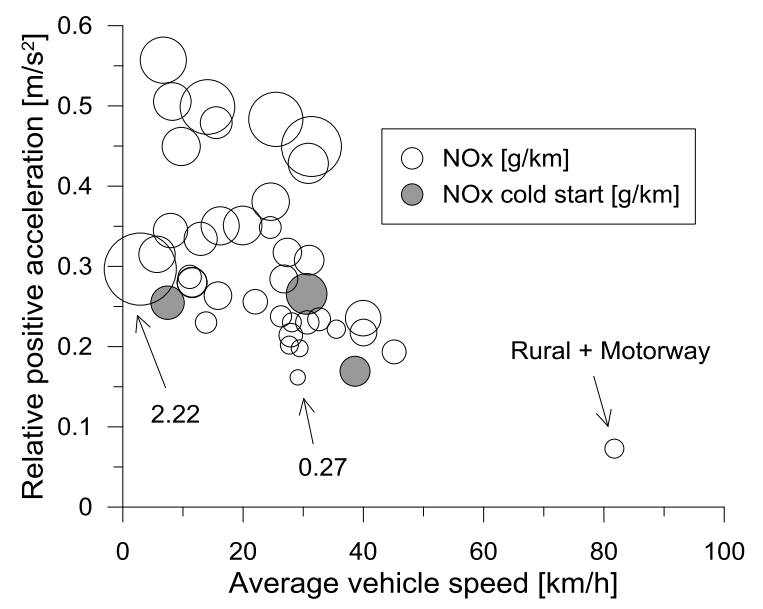

Figure 10. NOx emissions of each sub-trip as a function of the RPA and average speed.

As stablished in the RDE regulation, vehicle manufacturers can choose between two analytical methods to calculate the NOx emissions conformity factor (CF). The first one is the so-called moving averaging window (MAW) method [27]. Through this method, the test route is divided in sub-sections (windows), each of which accumulates a reference $\mathrm{CO}_{2}$ mass proportional to that emitted by the vehicle over the WLTC laboratory cycle. Then, the trip windows are classified into sub-sets of urban, rural and motorway categories using average speed bins (urban: $v<45 \mathrm{~km} / \mathrm{h}$, rural: $45 \leq \mathrm{v}<80$ $\mathrm{km} / \mathrm{h}$, motorway: $80<v \leq 145 \mathrm{~km} / \mathrm{h}$ ). As imposed in the RDE regulation, the windows share of each category for the PEMS test studied is at least $15 \%$ of the total number of windows (table 4). Thus, the PEMS test is classified as complete. After that, a statistical treatment is carried out to discard from analysis the windows that are not suitable. In this sense, the test route under investigation can be classified as normal because at least $50 \%$ of the windows of each category fall within the primary tolerances defined for the $\mathrm{CO}_{2}$ characteristic curve (Figure 11). Finally, the emissions rates for the different pollutants are calculated considering only the normal windows (Figure 13).

Table 4. Number of windows, completeness and normality factors of the PEMS test route for the MAW method.

\begin{tabular}{|l|c|c|c|c|}
\cline { 2 - 5 } \multicolumn{1}{c|}{} & Urban & Rural & Motorway & Total \\
\hline Number of windows [-] & 3165 & 1070 & 1019 & 5254 \\
\hline Share of total [\%] & 60.2 & 20.4 & 19.4 & 100 \\
\hline Completeness [-] & PASS & PASS & PASS & - \\
\hline Inside primary tolerances [-] & 1589 & 429 & 309 & 2152 \\
\hline Inside secondary tolerances [-] & 1576 & 641 & 710 & 3102 \\
\hline Valid windows [-] & 3165 & 1070 & 1019 & 5254 \\
\hline Normal windows [\%] & 50.2 & 59.9 & 69.7 & - \\
\hline Normality [-] & PASS & PASS & PASS & - \\
\hline
\end{tabular}




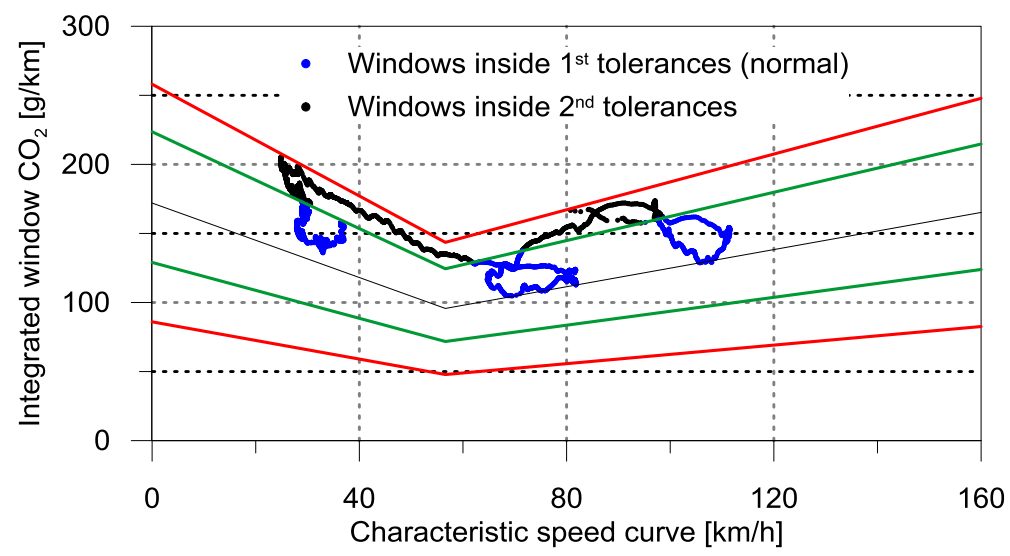

Figure 11. Moving averaging $\mathrm{CO}_{2}$ emissions versus average vehicle speed for the PEMS test route.

The second analytical method is the power binning (PB) method [28], also known as standard power frequency (SPF) [17]. This method relies on classifying the measured emissions during the PEMS test in accordance with the corresponding power at the wheels. The wheel power have to account for the power needed to overcome air resistance, rolling resistance, longitudinal inertia of the vehicle and rotation inertia of the wheels.

The data classification have to be done according to normalized wheel power classes $\left(P_{c, n o r m}, j\right)$ defined in the RDE regulation (table 5). Then, the emissions values are averaged per wheel power class considering the counts. A de-normalization procedure should be done to obtain the actual power classes $\left(P_{c, j}\right)$ for each PEMS test considering the vehicle characteristics [17]. Finally, the classified average emissions per power class shall be weighted by the time share to obtain the emission values for a PEMS test with a normal power distribution. The de-normalized power classes and the time share for the PEMS test under investigation, which fulfills the requirements imposed by the RDE regulation, are shown in table 5.

In the RDE regulation, the standard power frequencies are defined only for urban driving and for the total trip, and a separate evaluation of the emissions shall be made for both parts. The data classification by trip sections is done considering average speed bins (urban: $v \leq 60 \mathrm{~km} / \mathrm{h}$, rural: $60<\mathrm{v} \leq 90 \mathrm{~km} / \mathrm{h}$, motorway: $v>90 \mathrm{~km} / \mathrm{h}$ ). It is interesting to note that these speed bins differ from those proposed in the MAW method. Figure 12 shows the time share and average NOx, CO and HC emissions per power class for the urban period and total trip. A stated before, the time share of each power class is used to calculate the final emissions rates in $\mathrm{g} / \mathrm{km}$ for the urban period and total trip, individually. 
Table 5. Normalized and de-normalized power classes and time share for the PEMS test.

\begin{tabular}{|c|c|c|c|c|c|c|c|c|}
\hline \multirow{2}{*}{$\begin{array}{c}\text { Power } \\
\text { class }\end{array}$} & \multicolumn{2}{|c|}{$\mathrm{P}_{\mathrm{c}, \text { norm }, \mathrm{j}}$} & \multicolumn{2}{c|}{$\mathrm{P}_{\mathrm{c}, \mathrm{j}}[\mathrm{kW}]$} & \multicolumn{2}{c|}{ Urban } & \multicolumn{2}{c|}{ Total } \\
\cline { 2 - 9 } & From $>$ & to $\leq$ & From $>$ & to $\leq$ & $\begin{array}{c}\text { Counts } \\
{[-]}\end{array}$ & $\begin{array}{c}\text { Share } \\
{[\%]}\end{array}$ & $\begin{array}{c}\text { Counts } \\
{[-]}\end{array}$ & $\begin{array}{c}\text { Share } \\
{[\%]}\end{array}$ \\
\hline 1 & & -0.1 & - & -1.645 & 102 & 2.7 & 108 & 1.9 \\
\hline 2 & -0.1 & 0.1 & -1.645 & 1.645 & 1395 & 36.6 & 1424 & 25.5 \\
\hline 3 & 0.1 & 1 & 1.645 & 16.454 & 1949 & 51.1 & 2701 & 48.4 \\
\hline 4 & 1 & 1.9 & 16.454 & 31.262 & 318 & 8.3 & 1086 & 19.5 \\
\hline 5 & 1.9 & 2.8 & 31.262 & 46.071 & 39 & 1.0 & 215 & 3.9 \\
\hline 6 & 2.8 & 3.7 & 46.071 & 60.879 & 8 & 0.2 & 37 & 0.7 \\
\hline 7 & 3.7 & 4.6 & 60.879 & - & 2 & 0.1 & 6 & 0.1 \\
\hline 8 & 4.6 & 5.5 & - & - & - & - & - & - \\
\hline 9 & 5.5 & & - & - & - & - & - & - \\
\hline
\end{tabular}
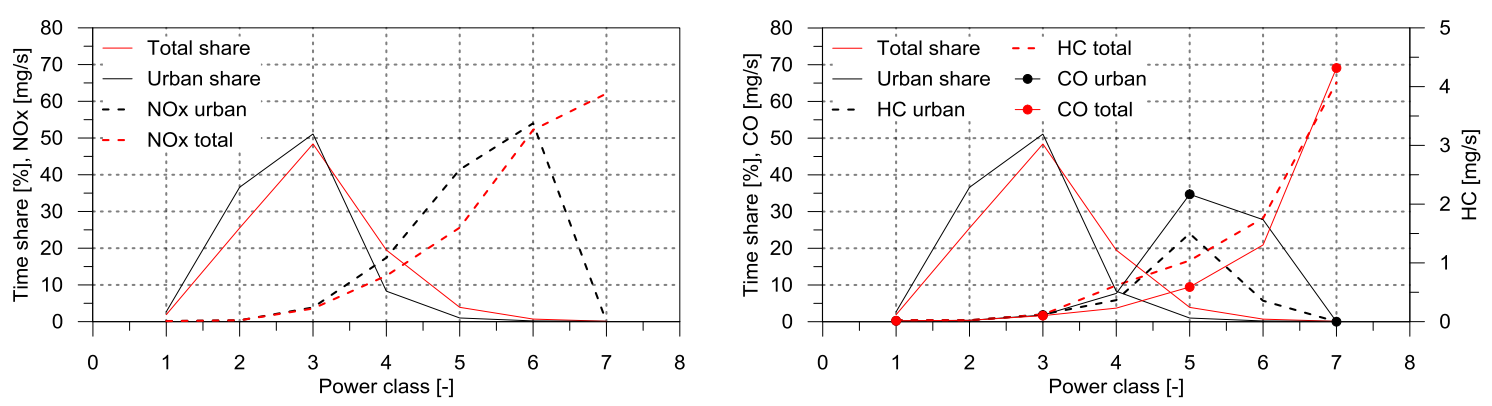

Figure 12. Time share and average NOx, $\mathrm{CO}$ and $\mathrm{HC}$ emissions per power class for the urban period and total trip.

Figure 13 shows the final emissions rates for the urban section and total trip calculated through the MAW and SPF methods. The calculations have been performed using the software provided by the PEMS manufacturer with all the configuration parameters following the RDE regulation (cold start period was discarded). As it can be seen, the NOx emissions rates are higher with the MAW method in both the urban $(+20 \%)$ and total trip (+10\%), which is consistent with previous works [29][30]. These differences are explained because the MAW method calculates the average emissions by applying the same contribution ratio to all driving ranges. By contrast, the SPF method increases the emissions contribution ratio for the driving ranges with low power (classes 1 to 3 ), which have greater time share and lower NOx emissions (Figure 12). Moreover, it is interesting to note that the speed bins used for classifying the data differ between both calculation methods. With these values, the NOx CF for the total trip calculated through both methods is $\mathrm{CF}_{\mathrm{MAW}}=2.61$ and $\mathrm{CF}_{\mathrm{SPF}}=2.35$, slightly exceeding the value proposed by the $\mathrm{RDE}$ regulation $(\mathrm{CF}=2.1)$. $\mathrm{CO}$ and $\mathrm{HC}$ emissions are higher with the SPF method, for which the RDE regulation has not established a CF up to the moment. 

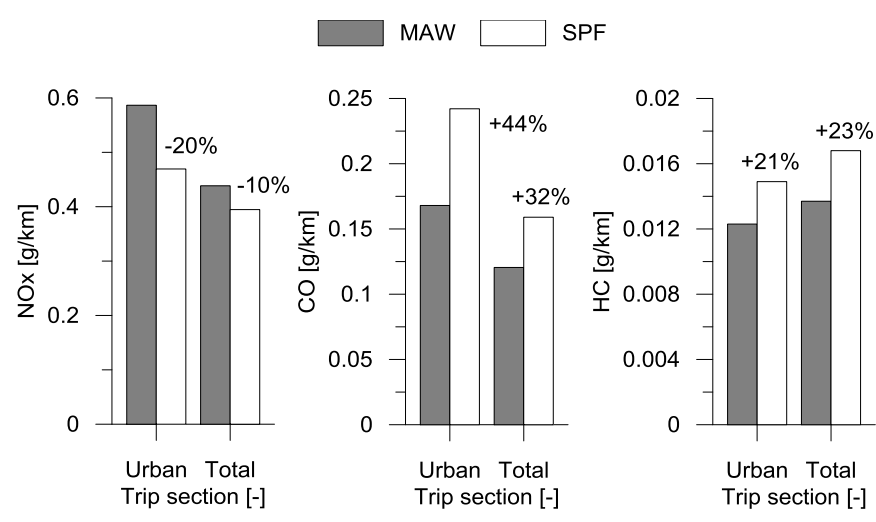

Figure 13. Emissions rates for the urban section and total trip calculated through both analytical methods.

The RDE regulation defines the cold start period as the first 300 seconds after the initial engine start, or the period until the coolant temperature reaches $70^{\circ} \mathrm{C}$, if this is shorter. In the case of the PEMS test, the coolant temperature reached $70{ }^{\circ} \mathrm{C}$ after 550 seconds, so that the cold start period is considered from 0 to 300 seconds ( $1.23 \mathrm{~km}$ covered). The analysis of the emissions rates during this period is of major interest because they are notably higher than during the rest of the route and typically occur in urban areas. Figure 14 shows the effect of the cold start period on the tailpipe emissions levels during the urban phase. As it can be seen, the removing of the cold start period from the urban data leads to a raw emissions reduction of $3.7 \%$ in $\mathrm{gNO} / \mathrm{km}, 42.5 \%$ in $\mathrm{gCO} / \mathrm{km}, 18 \%$ in $\mathrm{gHC} / \mathrm{km}$ and $2.3 \%$ in $\mathrm{gCO}_{2} / \mathrm{km}$ in this phase. Finally, comparing the results for the urban period (without excluding the cold start) with those shown in Figure 13, it is possible to see that MAW method reflects better the raw NOx emissions levels, while the SPF does it for the $\mathrm{CO}$ and $\mathrm{HC}$ emissions.
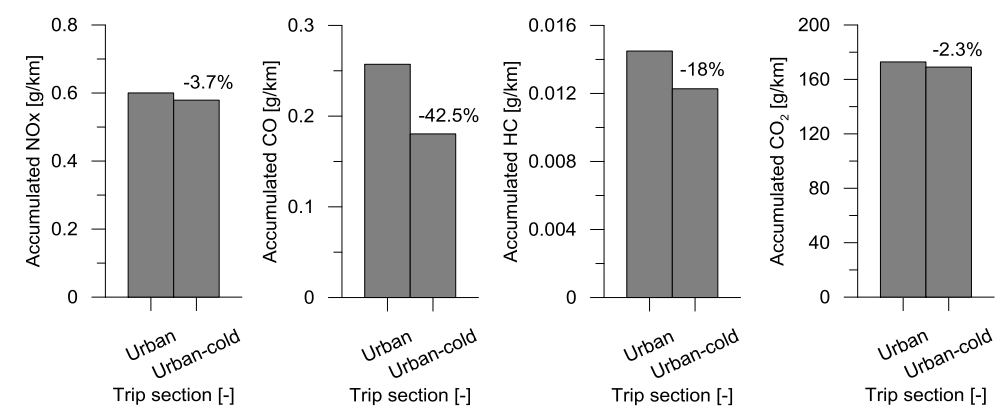

Figure 14. Comparison of the raw emissions levels in the urban phase with and without considering the cold start period.

\section{Conclusions}

This study has presented and analyzed the gaseous emissions from a Euro 6 light-duty diesel vehicle over a test route that fulfills the requirements imposed by the RDE regulation.

The first part of the study discussed the instantaneous and accumulated raw emissions results without removing the cold start period from the raw data. It has been shown that the greatest amount of $\mathrm{NOx}$ and $\mathrm{NO}_{2}$ are emitted during the urban section of the test route, confirming that lower speeds with more accelerations and decelerations lead to 
higher NOx emissions levels than constant high speeds. By contrast, the total $\mathrm{HC}$ and $\mathrm{CO}$ emissions levels are clearly driven by the levels emitted in the motorway section, with more than $60 \%$ share of the total emissions. In this sense, the MAW method reflects better the raw NOx emissions, while the SPF does it for the $\mathrm{CO}$ and $\mathrm{HC}$ emissions. Finally, the NOx CF for the total trip has been found to be 2.61 for the MAW method and 2.35 for the SPF, slightly higher than 2.1 (imposed by the RDE regulation).

The second part of the study has shown the influence of the analytical method on the emissions rates and the NOx conformity factor calculation. It has been shown that the differences between the two methods proposed in the RDE regulation range from $10 \%$ to $45 \%$ depending on the pollutant emission and the trip section considered (urban or total). This suggests that, for future stages of the regulation, the analytical methods should be revised to try to provide more homogeneous results. The effect of the cold start period (first 300 seconds) on the raw emissions has been shown to be strong for $\mathrm{CO}$, moderate for $\mathrm{HC}$ and low for NOx emissions.

The analysis presented in the manuscript bases on a single RDE cycle and will serve as a base for future works. In this sense, since the real driving cycles can differ significantly between each other, future works will entail testing more vehicles of different propulsion systems in a wider variety of test routes.

\section{Acknowledgments}

The authors gratefully acknowledge Mr. Juan Antonio López-Cascant for his contribution in performing the on-road test. The author J. Monsalve-Serrano acknowledges the financial support from the Universitat Politècnica de València under the Grant "Ayudas Para la Contratación de Doctores para el Acceso al Sistema Español de Ciencia, Tecnología e Innovación".

\section{References}

[1] Araghi Y, Kroesen M, Van Wee B. Identifying reasons for historic car ownership and use and policy implications: An explorative latent class analysis. Transport Policy, Volume 56, May 2017, Pages 12-18.

[2] González J, Otsuka Y, Araki M, Shiga S. Impact of new vehicle market composition on the light-duty vehicle fleet $\mathrm{CO}_{2}$ emissions and cost. Energy Procedia, Volume 105, May 2017, Pages 3862-3867.

[3] The Automobile industry Pocket Guide 2015-2016. European Automobile Manufacturers' Association's (ACEA). Brussels, 2016.

[4] Singh S, Kennedy C. Estimating future energy use and CO2 emissions of the world's cities. Environmental Pollution, Volume 203, August 2015, Pages 271-278.

[5] Fontaras G, Dilara P. The evolution of European passenger car characteristics 20002010 and its effects on real-world $\mathrm{CO}_{2}$ emissions and $\mathrm{CO}_{2}$ reduction policy. Energy Policy, Volume 49, October 2012, Pages 719-730.

[6] Myung C-L, Jang W, Kwon S, Ko J, Park S. Evaluation of the real-time de-NOx performance characteristics of a LNT-equipped Euro-6 diesel passenger car with various vehicle emissions certification cycles. Energy, Volume 132, 1 August 2017, Pages 356-369. 
[7] André M. The ARTEMIS European driving cycles for measuring car pollutant emissions. Science of The Total Environment, Volumes 334-335, 1 December 2004, Pages 73-84.

[8] Yamada H, Hayashi R, Tonokura K. Simultaneous measurements of on-road/invehicle nanoparticles and NOx while driving: Actual situations, passenger exposure and secondary formations. Science of The Total Environment, Volumes 563-564, 1 September 2016, Pages 944-955.

[9] Commission Regulation (EC) No 692/2008 of 18 July 2008 implementing and amending Regulation (EC) No 715/2007 of the European Parliament and of the Council on type-approval of motor vehicles with respect to emissions from light passenger and commercial vehicles (Euro 5 and Euro 6) and on access to vehicle repair and maintenance information. Off. J. Eur. Union L199, 1-136. European Commission, 2008.

[10] Sileghem L, Bosteels D, May J, Favre C, Verhelst S. Analysis of vehicle emission measurements on the new WLTC, the NEDC and the CADC. Transportation Research Part D: Transport and Environment, Volume 32, October 2014, Pages 70-85.

[11] Degraeuwe B, Weiss M. Does the New European Driving Cycle (NEDC) really fail to capture the NOX emissions of diesel cars in Europe?. Environmental Pollution, Volume 222, March 2017, Pages 234-241.

[12] Tutuianu M, Bonnel P, Ciuffo B, Haniu T, Ichikawa N, Marotta A, Pavlovic J, Steven H. Development of the World-wide harmonized Light duty Test Cycle (WLTC) and a possible pathway for its introduction in the European legislation. Transportation Research Part D: Transport and Environment, Volume 40, October 2015, Pages 61-75.

[13] Ko J, Jin D, Jang W, Myung C-L, Park S. Comparative investigation of NOx emission characteristics from a Euro 6-compliant diesel passenger car over the NEDC and WLTC at various ambient temperatures. Applied Energy, Volume 187, 1 February 2017, Pages 652-662

[14] Fu M, Ge Y, Wang X, Tan J, Liang B. NOx emissions from Euro IV busses with SCR systems associated with urban, suburban and freeway driving patterns. Science of The Total Environment, Volumes 452-453, 1 May 2013, Pages 222-226.

[15] Fontaras G, Franco V, Dilara P, Martini G, Manfredi U. Development and review of Euro 5 passenger car emission factors based on experimental results over various driving cycles. Science of The Total Environment, Volumes 468-469, 15 January 2014, Pages 1034-1042.

[16] Pathak S, Sood V, Singh Y, Channiwala S. Real world vehicle emissions: Their correlation with driving parameters. Transportation Research Part D: Transport and Environment, Volume 44, May 2016, Pages 157-176.

[17] Commission Regulation (EU) 2016/427 of 10 March 2016 amending Regulation (EC) No 692/2008 as regards emissions from light passenger and commercial vehicles (Euro 6). Off. J. Eur. Union L82, 1-98. European Commission, 2016.

[18] Kousoulidou M, Fontaras G, Ntziachristos L, Bonnel P, Dilara P. Use of portable emissions measurement system (PEMS) for the development and validation of passenger car emission factors. Atmospheric Environment, Volume 64, January 2013, Pages 329-338. 
[19] Bonnel P, Kubelt J. Heavy-duty engines conformity testing based on PEMS Lessons learned from the European pilot program. EUR Draft report. EC-JRC, 2010. Ispra, Italy.

[20] Larsson $\mathrm{H}$, Ericsson $\mathrm{E}$. The effects of an acceleration advisory tool in vehicles for reduced fuel consumption and emissions. Transportation Research Part D: Transport and Environment, Volume 14, Issue 2, March 2009, Pages 141-146.

[21] May J, Bosteels D, Favre C. An Assessment of Emissions from Light-Duty Vehicles using PEMS and Chassis Dynamometer Testing. SAE Int. J. Engines 7(3):2014, doi:10.4271/2014-01-1581.

[22] Commission Regulation (EU) 2016/646 of 20 April 2016 amending Regulation (EC) No 692/2008 as regards emissions from light passenger and commercial vehicles (Euro 6). Off. J. Eur. Union L109, 1-22. European Commission, 2016.

[23] On-board Emissions Measurement System OBS-ONE GS Unit, HORIBA (2016). http://www.horiba.com/automotive-test-systems/products/emissionmeasurement-systems/on-board-systems/details/on-board-emissionsmeasurement-system-obs-one-gs-unit-23645/ (accessed 26 June 2017).

[24] Nissan Pulsar specifications, Nissan (2017). www.nissan.es/vehiculos/nuevosvehiculos/pulsar/prestaciones.html (accessed 26 June 2017).

[25] Lee T, Park J, Kwon S, Lee J, Kim J. Variability in operation-based NOx emission factors with different test routes, and its effects on the real-driving emissions of light diesel vehicles. Science of The Total Environment, Volumes 461-462, 1 September 2013, Pages 377-385.

[26] Alvarez R, Weilenmann M, Novak P. Pollutant emissions from vehicles with regenerating after-treatment systems in regulatory and real-world driving cycles. Science of The Total Environment, Volume 398, Issues 1-3, 15 July 2008, Pages 8795.

[27] Prati M, Meccariello G, Della Ragione L, Costagliola M. Real Driving Emissions of a Light-Duty Vehicle in Naples. Influence of Road Grade. SAE Technical Paper 201524-2509, 2015, doi:10.4271/2015-24-2509.

[28] Hausberger S., Lipp S. Evaluation Methods for Real Drive Emission Tests of LDV for a Future Legislation Emissions in Real Driving Situations Demands for PEMS-Tests at LDV. Institute for Internal Combustion Engines and Thermodynamics - TU Graz, 2016.

[29] Varella R, Duarte G, Baptista P, Sousa L, Mendoza P. Comparison of Data Analysis Methods for European Real Driving Emissions Regulation. SAE Technical Paper 201701-0997, 2017, doi:10.4271/2017-01-0997.

[30] Kwon S, Park Y, Park J, Kim J, Cha J-S. Characteristics of on-road NOx emissions from Euro 6 light-duty diesel vehicles using a portable emissions measurement system. Science of The Total Environment, Volume 576, 15 January 2017, Pages 7077.
Abbreviations
CF: Conformity Factor
CLD: Chemiluminescence Detection
CO: Carbon Monoxide
$\mathrm{CO}_{2}$ : Carbon Dioxide 
DC: Direct Current

DCI : DIESEL COMMON-RAIL INJECTION

DI: Direct Injection

DOC: Diesel Oxidation Catalyst

DPF: Diesel Particulate Filter

FID: Flame Ionization Detection

GPS: Global Positioning System

HC: Hydro Carbons

ICE : Internal Combustion Engine

LNT: Lean NOx Trap

MAW: Moving Averaging Window

NDIR: Non-dispersive Infrared

NEDC: New European Driving Cycle

NOx: Nitrogen Oxides

$\mathrm{NO}_{2}$ : Nitrogen dioxide

NTE: Not To Exceed

OBD: On Board Diagnostics

PB: Power Binning

PEMS: Portable Emissions Measurement System

$\mathrm{P}_{c, \text { norm, }}$ : Normalized Wheel Power Class

$\mathrm{P}_{\mathrm{c}, \mathrm{j}}$ : De-normalized power classes

RDE: Real Driving Emissions

RPA: Relative Positive Acceleration

SCR: Selective Catalytic Reduction

SPF: Standard Power Frequency

WLTC: Worldwide harmonized Light duty Test Cycle 


\section{Appendix 1}

\begin{tabular}{|c|c|c|}
\hline & $\begin{array}{l}\text { RDE regulation (COMMISSION } \\
\text { REGULATION (EU) 2016/427) }\end{array}$ & Current study \\
\hline Dynamic conditions & $\begin{array}{l}\text { Data normalized by dynamic } \\
\text { conditions- dynamic conditions } \\
\text { encompass the effect of road } \\
\text { grade, head wind and driving } \\
\text { dynamics (accelerations, } \\
\text { decelerations) and auxiliary } \\
\text { systems }\end{array}$ & $\begin{array}{l}\checkmark \text { data was normalized for the } \\
\text { calculations with MAW and SPF } \\
\text { methods }\end{array}$ \\
\hline Data pre-processing & $\begin{array}{l}\text { T4253H- compound data } \\
\text { smoother (speed) }\end{array}$ & $\begin{array}{l}\checkmark \text { Speed data was smoothed } \\
\text { according to regulation for the } \\
\text { calculations with MAW and SPF } \\
\text { methods }\end{array}$ \\
\hline Urban driving & $\begin{array}{l}\text { The average speed of the urban } \\
\text { driving part of the trip should } \\
\text { be between } 15 \text { and } 40 \mathrm{~km} / \mathrm{h} \text {. } \\
\text { Stop periods, defined as vehicle } \\
\text { speed of less than } 1 \mathrm{~km} / \mathrm{h} \text {, shall } \\
\text { account for } 6-30 \% \text { of the time } \\
\text { duration of urban operation. } \\
\text { Urban operation shall contain } \\
\text { several stop periods of } 10 \mathrm{~s} \text { or } \\
\text { longer. If a stop period lasts } \\
\text { more than } 180 \mathrm{~s} \text {, the emission } \\
\text { events during the } 180 \mathrm{~s} \\
\text { following such an excessively } \\
\text { long stop period shall be } \\
\text { excluded from the evaluation. }\end{array}$ & $\begin{array}{l}\checkmark \text { Study average speed of } \\
\text { urban section } 21.5 \mathrm{~km} / \mathrm{h} \\
\checkmark \text { Study average stop periods } \\
26.53 \% \text { of urban time. } \\
\checkmark \text { Study contains stop periods } \\
\text { of more than } 10 \mathrm{~s} \\
\checkmark \text { Study does not contain stop } \\
\text { periods of more than } 180 \mathrm{~s}\end{array}$ \\
\hline Temperature & $\begin{array}{l}\text { Greater than or equal to } 273 \mathrm{~K} \\
\left(0^{\circ} \mathrm{C}\right) \text { and lower than or equal } \\
\text { to } 303 \mathrm{~K}\left(30^{\circ} \mathrm{C}\right)\end{array}$ & $\begin{array}{l}\checkmark \text { Study temperature between } \\
15-20^{\circ} \mathrm{C}\end{array}$ \\
\hline Altitude & $\begin{array}{l}\text { Altitude lower or equal to } 700 \\
\text { metres above sea level } \\
\text { The positive altitude gain shall } \\
\text { be less than } 1200 \mathrm{~m} / 100 \mathrm{~km} \\
\text { The start and the end point } \\
\text { shall not differ in their elevation } \\
\text { above sea level by more than } \\
100 \mathrm{~m} \text {. }\end{array}$ & $\begin{array}{l}\checkmark \text { Study conducted around sea } \\
\text { level } \\
\checkmark \text { Positive altitude gain is } 321 \\
\mathrm{~m} / 100 \mathrm{~km} \\
\checkmark \text { Start and end point differ in } \\
\text { their elevation by } 18 \mathrm{~m}\end{array}$ \\
\hline Time & $\begin{array}{l}\text { The trip duration shall be } \\
\text { between } 90 \text { and } 120 \text { minutes }\end{array}$ & $\checkmark$ Trip duration 91 minutes \\
\hline Calibration of analysers & $\begin{array}{l}\text { One should conduct the zero } \\
\text { and span calibration of } \\
\text { analysers at an ambient } \\
\text { temperature that resembles, as } \\
\text { closely as possible, the } \\
\text { temperature experienced by } \\
\text { the test equipment during the } \\
\text { RDE trip }\end{array}$ & $\begin{array}{l}\checkmark \text { Calibrations done at ambient } \\
\text { temperature }\end{array}$ \\
\hline
\end{tabular}




\begin{tabular}{|c|c|c|}
\hline Speed accuracy & $\begin{array}{l}\text { If vehicle speed is used to } \\
\text { determine parameters like } \\
\text { acceleration, the product of } \\
\text { speed and positive acceleration, } \\
\text { or RPA, the speed signal shall } \\
\text { have an accuracy of } 0,1 \% \\
\text { above } 3 \mathrm{~km} / \mathrm{h} \text { and a sampling } \\
\text { frequency of } 1 \mathrm{~Hz} \text {. } \\
\text { Vehicle velocity shall normally } \\
\text { not exceed } 145 \mathrm{~km} / \mathrm{h}\end{array}$ & $\begin{array}{l}\checkmark \text { Speed recorded to } 3 \text { decimal } \\
\text { places } \\
\checkmark \text { Sampling frequency of } 1 \mathrm{~Hz} \\
\checkmark \text { Speed does not exceed } 145 \\
\mathrm{~km} / \mathrm{h}\end{array}$ \\
\hline \multirow[t]{2}{*}{$\begin{array}{l}\text { Classification of urban/ rural/ } \\
\text { motorway (Binning of results) }\end{array}$} & $\begin{array}{l}\text { Urban } 0 \text { to } \leq 60 \mathrm{~km} / \mathrm{h} \\
\text { Rural }>60 \text { to } \leq 90 \mathrm{~km} / \mathrm{h} \\
\text { Motorway }>90 \mathrm{~km} / \mathrm{h}\end{array}$ & $\begin{array}{l}\checkmark \text { sections classified using this } \\
\text { criteria }\end{array}$ \\
\hline & $\begin{array}{l}\text { The trip shall consist of } \\
\text { approximately } 34 \% \text { per cent } \\
\text { urban, } 33 \% \text { per cent rural and } \\
33 \% \text { per cent motorway } \\
\text { The minimum distance of each } \\
\text { operation: urban, rural and } \\
\text { motorway, shall be } 16 \mathrm{~km}\end{array}$ & $\begin{array}{l}\checkmark \text { percentage share for each } \\
\text { section is } 32.2 \% \text { urban, } 32.7 \% \\
\text { rural and } 35 \% \text { mortorway } \\
\checkmark \text { distance of each section is } \\
21.7 \mathrm{~km} \text { urban, } 22.05 \mathrm{~km} \text { rural } \\
\text { and } 23.61 \mathrm{~km} \text { mortorway }\end{array}$ \\
\hline Cold start & $\begin{array}{l}\text { The cold start period covers the } \\
\text { first } 5 \text { minutes after initial start } \\
\text { of the combustion engine, or } \\
\text { until the coolant temperature } \\
\text { reaches } 343 \mathrm{~K}\left(70^{\circ} \mathrm{C}\right)\end{array}$ & $\begin{array}{l}\checkmark \text { The cold start period was } \\
\text { removed for calculating with } \\
\text { MAW and SPF methods }\end{array}$ \\
\hline Moving average windows & $\begin{array}{l}\text { The instantaneous emissions } \\
\text { calculated according should be } \\
\text { integrated using a moving } \\
\text { averaging window method, } \\
\text { based on the reference } \mathrm{CO}_{2} \\
\text { mass. }\end{array}$ & $\begin{array}{l}\checkmark \text { Official software from the } \\
\text { PEMS manufacturer used to } \\
\text { calculate the NOx conformity } \\
\text { factor through the } \mathrm{CO}_{2} \mathrm{MAW} \\
\text { method }\end{array}$ \\
\hline
\end{tabular}

